\title{
LA EXPERIENCIA COMO PARADIGMA DEL NEXO ENTRE EL HOMBRE Y DIOS
}

\author{
PAOLO PONZIO \\ Università degli Studi di Bari Aldo Moro
}

\begin{abstract}
RESUMEN: El artículo muestra como a partir del concepto de experiencia Xavier Zubiri analiza la relación entre hombre y Dios, y constituye una importante aportación filosófica frente al reduccionismo del pensamiento contemporáneo. Su pensamiento muestra toda su tarea cuando se empieza a comprender la unidad de pensamiento que hay entre metafísica de la realidad, filosofía de la inteligencia y pensamiento metafísico-religioso.
\end{abstract}

PALABRAS CLAVE: experiencia, Realidad, Antropología, Hombre, Dios, Inteligencia sentiente, Zubiri.

\section{Experience as a paradigm of nexus between Man and God}

ABSTRACT: The article shows how the concept of experience, elaborated by Xavier Zubiri, explores the relationship between man and God, and represents an important philosophical contribution against the reductionism of contemporary thought. His thinking shows its task when we begin to understand the unity of thought between reality metaphysics, philosophy of intellect and metaphysical-religious thought. Xavier Zubiri's interest is always constituted by a unity and wholeness.

KEY WORDS: experience, Reality, Anthropology, Man, God, Sentient Intelligence, Zubiri.

«En definitiva, estamos lanzados por las cosas reales, por la religación, a la búsqueda de la realidad divina. Hacerse persona es ir buscando la realidad divina ${ }^{1}$.

Con estas palabras Xavier Zubiri parece indicar, pocos días antes de fallecer $^{2}$, cuál es la tarea del hombre en busca de Dios, y cuáles son las dimensiones peculiares de su «experiencia» de Dios. «Dios, experiencia del hombre»y «el hombre, experiencia de Dios»: en éstas dos locuciones se puede sintetizar todo el pensamiento de Zubiri alrededor del nexo entre hombre y Dios: "por razón de Dios, Dios es experiencia del hombre. Por razón del hombre, el hombre es experiencia de Dios» $»^{3}$.

Ninguno de estos dos términos tiene experiencia del otro: el hombre no tiene experiencia de Dios, ni puede haberla; no está en las posibilidades del hombre tener una experiencia semejante, no por su capacidad sino por su aptitud. El hombre es formalmente experiencia de Dios, porque Dios se nos da en forma de realidad-fundamento.

La posición filosófica de Zubiri asume una connotación unitaria cuando se empieza a comprender la unidad de pensamiento que hay entre metafísica de la realidad, filosofía de la inteligencia y pensamiento metafísico-religioso. El

1 Zubiri, X. (2012), Hombre y Dios, (cit. HD) Madrid: Alianza Editorial, p. 122.

2 Según cuanto emerge de la colocación en el Archivo de la Fundación Zubiri, este texto manuscrito, parece ser escrito entre el 15 y el 19 de septiembre del 1983. Cf. HD, p. 119.

3 HD, p. 524. 
interés de Xavier Zubiri es siempre constituido por una unidad y totalidad. Hablar del infinito es posible solo desde lo finito: así para comprender la trascendencia se necesita mirar en profundidad lo que tenemos como más valioso: la "realidad de suyo".

«La trascendencia de Dios no es un estar más allá de las cosas, sino que, al revés, la trascendencia es justamente un modo de estar en ellas, aquel modo según el cual éstas no serían reales en ningún sentido sino, por así decirlo, incluyendo formalmente en su realidad la realidad de Dios, sin que por ello Dios sea idéntico a la realidad de las cosas» ${ }^{4}$.

El concepto de trascendencia, según cuanto nos dice Zubiri, indica un carácter de lo real, un carácter de las cosas en la realidad más profunda: es una presencia formal e intrínseca de todo, a través de la cual es evidente el fundamento propio de lo real en cuanto tal. Por eso el filósofo habla de "modo de ser" de las cosas. La trascendencia es el modo a través del cual Dios está en las cosas, existe en ellas. Es, por tanto, una trascendencia en las cosas, al fondo de ellas, y no allende de ellas ${ }^{5}$.

Esto es lo que Zubiri explica en las primeras páginas de Inteligencia y razón, cuando introduce el concepto de razón, la intelección pensante de lo real. Tal intelección es una intelección allende el campo de realidad, allende la realidad objetual. El pensamiento va allende las cosas, pero éste allende no es un sobrepasar la realidad sino, por el contrario, es un ir en profundidad: "allende" no es algo meramente "otro" sino que es otro "por" ser el "aquende" lo que es» ${ }^{6}$. Por éste motivo, pensar allende significa pensar lo que últimamente es aquende. El "por" indica, según el filósofo vasco, ir en profundidad, ir al fondo de las cosas, de la realidad. Y esta intelección del más allá en el "más aquí" es tal porque las cosas nos dan de que pensar y obligan nuestro conocimiento. Es éste un ejemplo del cambio de paradigma que Zubiri desea aportar con su pensamiento: no somos nosotros que pensamos en las cosas, sino que son las cosas que nos inducen a pensar. Y sin embargo, una tal posición está todavía demasiado cerca de la fenomenología de marca husserliana. La distancia de Husserl, me parece, se cumple en el análisis zubiriano, cuando se introduce el concepto de medida: la medida de la razón. ¿De qué medida se trata? ¿Si la razón es destinada a llegar a la profundidad de la realidad, cuál puede ser su medida? Es —nos dice Zubiri- una medida original: un principio en cuanto origen. Es un fundamento que sabe de sí mismo. Se llega, así, a conocer la realidad no como objeto, sino como fundamento: es la realidad-fundamento.

4 HD, p. 192.

5 Cfr. HD, p. 192.

6 IRA, p. 944. Por Inteligencia sentiente adoptamos las siguientes abreviaciones: Inteligencia sentiente. Inteligencia y realidad, (cit. IRE); Inteligencia y logos, (cit. IL); Inteligencia y razón, (cit. IRA). Seguimos la siguiente edición: X. ZuBIRI (2008), Intelligenza senziente, edición español-italiano a cargo de Paolo Ponzio y Oscar Barroso, Milano: Bompiani. 
«"La” realidad, en efecto, está aquí actualizada, nos está aquí presente, no como lo están "las" realidades, es decir como realidad-objeto, sino que está actualizada y nos está presente en sí misma y formalmente como realidadfundamento, o si se quiere como fundamento real. Es una diferencia esencial. El fundamento es realidad, pero realidad cuyo carácter de realidad consiste justamente en fundamentar realmente» ${ }^{7}$.

Tal realidad-fundamento está unida a la realidad-objeto: la objetualidad y la fundamentalidad de la realidad no son dos caras de una cosa, pues — por el contrario- una cosa por ser tal no puede que contener en sí misma su fundamentalidad. La realidad en cuanto abierta es lo que da que pensar, y este dar constituye la realidad en su principio de intelección pensante.

No se trata de un principio particular, sino del principio de todos los principios de la razón que es la «realidad»: la realidad en su físico e idéntico carácter: "Y en este sentido, digo que realidad es principio último: es último en el sentido de que su intelección es lo que constituye el principio de la razón en cuanto tal. Es ultimidad principial $»^{8}$.

Pero, como dice Zubiri en el curso de su análisis sobre el camino de la razón, la «realidad-fundamento no es realidad absoluta. Es un grave error de Hegel. La marcha hacia la profundidad no es el despliegue de un saber absoluto. La profundidad es siempre una dimensión abierta, y por esto la razón no es saber absoluto sino intelección abierta en profundidad»"

Por eso, como amaba repetir Zubiri, con las palabras de Agustín en su De Trinitate: "Busquemos como buscan los que aún no han encontrado, y encontremos como encuentran los que aún han de buscar, porque cuando el hombre ha terminado algo no ha hecho sino comenzar» ${ }^{10}$.

Tal carácter de fundamentalidad de la realidad de Dios en las cosas explica, más que otro, el concepto de trascendencia. Contra todo reduccionismo ontológico, según el cual Dios no puede darse si no como ente sumo, y más allá de toda explicación antropológica o cósmica de la existencia de Dios, Zubiri llega a una tercera vía de justificación de Dios que evita la disociación y fragmentación de las primeras dos vías, llegando a una idea de Dios en cuanto realidad suprema. Realidad y no ente, ya que también por el concepto de Dios vale aquel criterio universal de la filosofía zubiriana, según el cual el ser es un acto ulterior de lo real en cuanto tal. Dios, por lo tanto, no es ente supremo, ser subsistente cuyo primer atributo es la infinitud, sino realidad suprema. Se puede decir, retomando una famosa afirmación de Levinas, que Dios existe más allá del ser. Tal realidad de Dios, luego, se dice "suprema" por el carácter de plenitud y absolutidad que compite a tal realidad. Aquella de Dios, en efecto, es una realitas simpliciter, a diferencia de todas las otras realidades que se dan en función de otro: la realidad de Dios, en cambio, no tiene delante de sí otro

\author{
IRA, p. 952. \\ IRA, p. 958. \\ IRA, p. 1110. \\ 10 IRA, p. 1234 (cfr. S. Agustín, De Trinitate, IX, 1).
}


que sí mismo. Es, por lo tanto, últimamente realidad absolutamente absoluta, a diferencia de la realidad humana que es solo "relativamente absoluta» ${ }^{11}$.

Dios es la realidad fundante, aquella realitas fundamentalis, en la cual las cosas son fundadas, siempre en independencia respecto a Dios ${ }^{12}$. La fundamentalidad constituye, entonces, no un carácter constitutivo de la realidad de Dios, sino también su consecuencia. Como el mismo Zubiri subraya: «la fundamentalidad no es su ratio essendi. Es, a lo sumo, su ratio cognoscendi» ${ }^{13}$. Y este pasaje parece asumir una precisa importancia: el hombre no puede llegar a un conocimiento directo de Dios, sino en cuanto fundamento de las cosas reales. Es precisamente a través de la realidad que Dios se hace cognoscible al hombre. ¿De qué modo? A través del acto del donarse, o mejor, de la donación como acto: «Dios está fundamentando las cosas como un absoluto dar de sí» ${ }^{14}$. Es la experiencia del don que nos permite conocer a Dios en cuanto realidad que funda lo real.

La idea de don elimina de raíz, según Zubiri, dos grandes errores: aquello de pensar que la presencia de Dios en las cosas es momento de la única realidad divina y, por lo contrario, aquello de retener también, para ser distinto de las cosas, que Dios tiene que ser más allá de la escena del mundo, últimamente ausente al mundo mismo. El acto de la donación, en cambio, vuelve constitutiva la presencia de Dios en las cosas: él en las cosas está haciendo sí que sean reales, está haciendo sí que sean de suyo. El aspecto de la donación es así el aspecto originario, primigenio, de la trascendencia divina: ella, como dice el mismo filósofo español, «es una trascendencia fontanal» ${ }^{15}$.

Tal naturaleza originaria de la presencia de Dios en las cosas nos introduce al tema de la posibilidad del acceso de Dios por parte del hombre. ¿Qué significa acercarse a Dios? Ciertamente, se trata de un acto plenamente humano, un acto que el hombre ejecuta y con el cual se acerca a Dios; pero, ¿cuál es su naturaleza? ¿Se puede decir que sea un acto puro intelectivo, o volitivo? «Evidentemente todos estos actos son momentos o aspectos del acto único en que la vida del hombre formalmente consiste: la constitución y configuración de su ser relativamente absoluto, de su Yo» ${ }^{16}$. Es, en efecto, en el yo que el hombre se acerca a Dios: «el hombre, velis nolis, al hacer su Yo con las cosas reales en cuanto reales, está haciendo su Yo en Dios (ultimidad), con Dios (posibilidad) y por Dios (impelente) ${ }^{17}$. Pero esta dinámica no constituiría un acceso real a Dios si no se soportase en la idea de trascendencia; como hemos dicho, Dios está sí presente en las cosas, pero sin una identificación. Dios está en las cosas

11 Cf. todos los pasajes en HD, pp. 63-69.

12 Zubiri no puede olvidar que su teoría sobre el concepto de trascendencia en las cosas puede ser considerada mas cercana a una forma de panteísmo. Cfr. HD, pp. 468-469:

13 HD, p. 190.

14 HD, p. 191.

15 HD, p. 195.

16 HD, p. 199.

17 HD, p. 200. 
y estas en el darme su propia realidad me da, en alguna manera, Dios. Pero eso no es todo, porque el hombre no se mueve en Dios simplemente porque se mueve en la realidad; por eso, el acceso a Dios resulta a posteriori con respecto a las cosas, casi un acceso per accidens. Solo una trascendencia pensada como fundamentalidad en las cosas asegura un acceso a Dios por sí mismo y no per accidens. Tal acceso, por lo tanto, no se constituye en los términos de un encuentro (no es una capacidad del hombre aquella de encontrar a Dios), sino en términos de un regreso. La realidad de Dios es una realidad que se halla en las cosas reales, que son tales precisamente porque son en Dios: no somos nosotros, por tanto, que vamos hacia Dios, ni lo encontramos en las cosas, sino en ellas nos hallamos regresados a Dios.

\section{El acceso a Dios: (1) a parte DeI}

El tema del regreso aclara cuál es el dinamismo propio del acercarse a Dios. La accesibilidad constituye, en efecto, un carácter propio de Dios, no del hombre. Es Dios que se hace constitutivamente accesible al hombre, donándose al hombre en las cosas, en virtud de su trascendencia interpersonal que se manifiesta en su verdad al hombre.

Cuando decimos que las cosas son reales en Dios, señalamos una presencia formal de Dios en las cosas, presencia que Zubiri explica en términos de una realidad personal: «las cosas reales son la presencia personal de Dios ${ }^{18}$. Tal presencia, luego, se desarrolla en diferentes modos, según la naturaleza, cerrada o abierta, de la realidad. En el caso de "esencias cerradas", en efecto, la presencia de Dios es tan solo identificante: las cosas son constituidas en sí mismas; en el caso, en cambio, de "esencias abiertas", es decir, en el hombre, la presencia de Dios es "suificante": Dios es accesible al hombre propiamente porque el hombre es persona. La trascendencia de Dios en el hombre se traduce, así, en una trascendencia interpersonal. Lejos de todo antropomorfismo, esta trascendencia no puede explicarse, según Zubiri, en términos de una relación "yo-tú". Es ciertamente inevitable que el hombre en el diálogo con esta presencia pueda llamarla "tú", pero, siempre necesita aclarar que tal posibilidad solo puede ser fundada sobre algo que precede a la relación. Es la trascendencia interpersonal de Dios en el hombre la que hace posible la relación humana del yo con un tú, no viceversa. Tal trascendencia asume el carácter de la tensión, una tensión entre el absoluto de Dios que funda y que, por tanto, hace actual el absoluto del hombre.

En esta dinámica de la trascendencia interpersonal, Dios se manifiesta al hombre como verdad. Ésta es la cumbre de la accesibilidad de parte de Dios. ¿De cuál verdad se trata? Sabemos que Zubiri, en el curso de su trilogía sobre la inteligencia ha evidenciado la dificultad de definir la verdad en términos de

18 HD, p. 203. 
una conformidad, o adecuación (adaequatio) del pensamiento a lo real. Cada adecuación, en efecto, tiene que corresponder a una plenitud absoluta de conformidad que no se da en la realidad. En el afirmar "este papel es blanco", se dice algo conforme a este papel, pero no se expresa adecuadamente el color blanco de este papel. La adecuación es, por tanto, un procedimiento que puede darse solo en un mundo ideal, no en lo que es "en realidad"; es un procedimiento gradual en el cual de una parte la conformidad se hace más adecuada, y de la otra, la verdad en su movimiento se dirige en modo determinado y establece un enfoque hacia la adecuación ${ }^{19}$.

«Esto - explica Zubiri- significa no que la realidad es tal como yo la afirmo, sino que aun siéndolo, sin embargo la conformidad misma es como el índice de un camino, cuya verdad consiste en que si lo recorriéramos totalmente habríamos encontrado la adecuación que se busca $»^{20}$.

Cada conformidad representa, así, una fase hacia la adecuación. Pero esta estructura pertenece a la dinámica de la verdad dual que es dirección hacia la adecuación, índice hacia lo que acontece ${ }^{21}$. La intelección afirmativa "este papel es blanco" constituye una conformidad que gradualmente indica una remota adecuación en lejanía. De aquí el hecho que cada juicio, cada verdad dual es estructuralmente aproximación: una aproximación gradual a lo real y una aproximación a lo que debe ser una verdad adecuada. La entera obra del saber humano es, por eso, una aproximación intelectiva a la realidad.

Pero el tema de la verdad no se agota en el interior del procedimiento decisional o afirmativo, propio de la intelección afirmativa. Al contrario, bien visto, una verdad como conformidad puede ser dada solo en virtud de una verdad previa: la verdad real:

«La cosa real es aprehendida como real en y por sí misma: es "de suyo" lo que es. Como este momento de formalidad es un prius de las cosas, resulta que la realidad no consiste formalmente ni se agota forzosamente en ser inteligida. En su virtud, por inteligir lo que la cosa realmente es, diremos que la intelección es verdadera. Lo que la mera actualización de lo real añade a la realidad es, pues, su verdad ${ }^{22}$.

El tema de la verdad en Zubiri - tal como emerge en el presente texto de Inteligencia y realidad - es una consecuencia propia de la actualidad intelectiva. Hay una relación directa entre actualidad y verdad; la verdad parece ser casi una "producción" de la actualidad al interior de la realidad. Así, el problema de la verdad no termina por añadirse al acto intelectivo, no es otro componente

19 Cf. IL, pp. 800-801.

20 Ibid.

21 A este propósito, como había escrito en Naturaleza, historia, Dios, Zubiri recuerda el célebre texto de Heráclito (fr. 93) según el cual «el oráculo de Delfos ni declara ni oculta, sino que indica, significa (semaínei), lo que va a ocurrir» (IL, p. 804).

22 IRE, pp. 326-328. 
más, sino que se configura como una visión especial del mismo acto intelectivo con el cual se aprehende primordialmente lo real.

Normalmente se considera el tema de la verdad en conexión con las cualidades de una afirmación, olvidando que la afirmación, en cuanto tal, es tan solo un modo de intelección. El concepto de verdad, en cambio, no concierne solo al modo afirmativo de intelección, sino a toda intelección en cuanto tal. La verdad, entonces, es intelección en cuanto aprehende lo real presente como real. Ella, en cuanto tal, no añade nada a la realidad sino la pura actualización. Con esto Zubiri no quiere decir que sean la misma cosa verdad y realidad. No se trata de realidad idéntica, ni de realidad correlacionada, ya que si es verdadero que cada verdad implica la realidad, no toda realidad implica la verdad. Es la realidad, entonces, el fundamento de la verdad, lo que da verdad a la intelección. "Verdad es pura y simplemente el momento de la real presencia intelectiva de la realidad ${ }^{23}$ : es decir, es un momento de pura actualización de lo real. Esta verdad que Zubiri llama verdad real, en oposición sea a la concepción kantiana — según la cual la verdad es únicamente conciencia objetiva- sea a aquella de matriz racionalista e idealista - según la cual la verdad consiste en la afirmación lógica-, depende propiamente de la aprensión primordial de realidad, y representa uno de los puntos de mayor novedad de la filosofía de Zubiri, determinando también el sistema conceptual del problema de la verdad en los demás modos de intelección sentiente: el logos y la razón. ¿Pero, como se caracteriza tal verdad real? En cuanto verdad primaria y radical de la inteligencia sentiente tal verdad real, no añadiendo nada a la realidad en cuanto tal, no se identifica con ella. Es una especie de calificación intrínseca que halla su colocación en la actualidad. Verdad es, entonces, el hecho de que las cosas permanecen presentes en la intelección como reales. Verdad es, así, últimamente ratificación: "He aquí la índole esencial de la verdad real: lo real está "en" la intelección, y este “en" es ratificación» ${ }^{24}$.

Tal concepto de ratificación, según Zubiri, es de extrema relevancia porque profundiza la distancia entre una idea de verdad en cuanto referida a cuanto de una cosa real se puede concebir o se afirma, y la idea de una verdad real originaria, tan solo en cuanto actualiza lo real en cuanto tal. Es ésta la idea de una verdad simple, una verdad con la cual no se sale fuera de lo real hacia un concepto, hacia una afirmación o hacia una razón ${ }^{25}$.

23 IRE, p. 328.

24 IRE, p. 332.

25 Continúa Zubiri, anteponiendo temáticas que serán tratadas en las otras dos partes de la obra sobre la Inteligencia sentiente:: «Si volvemos a la cosa real desde su concepto, es la verdad como autenticidad. Si volvemos a la cosa real desde una afirmación, es la verdad como conformidad. Si volvemos a la cosa real desde su razón, es la verdad como cumplimiento. Como veremos, esta tercera forma tampoco ha sido considerada por la filosofía clásica. Autenticidad, conformidad y cumplimiento son tres formas de verdad dual. »(IRE, p. 334). 
La verdad real participa de la tripartición de la realidad distinguiéndose en tres dimensiones - la riqueza, el qué y la estabilidad — de las cuales dependen los modos a través de los que puede decirse la misma verdad. La totalidad de la realidad, en efecto, se ratifica en riqueza según una modalidad específica que el filósofo español denomina manifestación; mientras "el qué" depende de la ratificación de la coherencia de la realidad según una modalidad denominada firmeza. En fin la realidad dura se ratifica en la estabilidad según una modalidad propia, llamada constatación. Estos tres modos propios de ratificación - manifestación, firmeza y constatación - derivan directamente del uso lingüístico diferente que la misma idea de verdad ha asumido en las más importantes lenguas antiguas: el griego, el latín y el hebreo. Y aquí, como se ve, retoma la idea de una correspondencia entre las diversas tradiciones culturales y filosóficas. La raíz del término de verdad constituye, en efecto, un importante test para verificar la credibilidad de las tres modalidades con las cuáles la realidad viene ratificada: el ser griego (es-), la certeza latina (uer-) y el ser patente hebraico (la- $d h-)$ representan desde el punto de vista lingüístico aquella única idea de verdad real a la cual alude el filósofo. Cada verdad real, en efecto, posee indisolublemente las tres dimensiones que son congéneres como momentos estructurales de la primaria actualización de una cosa real. Es interesante, en fin, anotar el hecho de que tal momento de ratificación constituye precisamente la fuerza de la realidad en la intelección. La verdad real siendo pura actualización de lo real no es un procedimiento que tiene como punto de partida el que aprehende, sino la cosa real que nos posee con su fuerza de imposición. No somos nosotros los que poseemos la verdad real, sino al contrario: la verdad real nos ha poseído por la fuerza de la realidad ${ }^{26}$.

Las tres dimensiones de la verdad real pertenecen al modo a través del cual Dios se manifiesta. En cuanto realidad absolutamente absoluta, él funda la realidad según tal triple carácter, y es al contrario precisamente a través de tal triple manifestación que se hace accesible al hombre: las cosas reales constituyen, en efecto, la forma concreta de la verdad real de Dios y representan, por tanto, «la accesibilidad a la realidad verdadera en que Dios consiste» ${ }^{27}$.

Tal accesibilidad, luego, en el caso del hombre, asume una característica peculiar importante: la presencia de Dios en el hombre que tiene la particularidad de una relación interpersonal. Como ya se dijo, se realiza en una tensión dinámica a través de la cual Dios dona al hombre su ser, dona al hombre su yo: «Dios me da el que yo sea Yo y haga mi Yo con toda su riqueza, con toda su firmeza, con toda su efectividad $\aleph^{28}$. La realidad verdadera del hombre es, por eso, la concreción de la accesibilidad de Dios en su verdad.

26 Cf. la octava apéndice en IRE, pp. 342-346.

27 HD, p. 209.

28 HD, p. 210. 
2. El aCceso a Dios: (2) A PARTE HOMINIS

Lo que hemos dicho hasta aquí muestra, sin duda alguna, que la accesibilidad de Dios no es algo extrínseco a la relación hombre-Dios, sino que pertenece al dinamismo interno de la misma relación, de la misma tensión interpersonal: la presencia de Dios en el hombre es la presencia de un Dios accesible en sí y para sí. Por tanto el acceso a parte Dei constituye ya un primer acceso a parte hominis.

Sin embargo, para comprender plenamente la accesibilidad de parte del hombre es necesario que apelemos a un concepto que hasta aquí ha permanecido en la sombra, escondido en los pliegues de nuestro discurso: el concepto de religatio, como aptitud radical del hombre. Sin tal concepto, en efecto, no es posible realizar aquel acceso interno al divino por parte del hombre. La religación, o religio, no es una propiedad que el hombre puede o no tener, sino que se configura como una dimensión formal de la persona humana, a través de la cual se realiza aquella dependencia estructural de nuestra persona de la realidad. No se trata, por tanto, de una obligación moral, o de un sentimiento de dependencia, sino de una experiencia de posesión de la realidad sobre el hombre: es el poder de lo real que se apodera de mí, religándome a sí. La religatio, por tanto, no se explica en un ir "hacia" algo que permite nuestra perfección, sino en un "venir de" algo que preliminarmente nos hace ser. Se puede decir que nuestro ir está determinado por el reconocimiento de un origen desde la cual descendemos ${ }^{29}$. ¿Qué es este origen, si no la presencia fundante de Dios en las cosas? En la religación, por tanto, nosotros estamos empujados físicamente por el poder de lo real, inducidos a ir hacia el fundamento de lo real, y eso porque es Dios mismo que nos atrae hacia él. En la tensión dinámica interpersonal, en virtud de la religación, se realiza una pre-tensión que nos atrae hacia Dios, y a la cual el hombre, sin embargo, se inclina. Sin tal inclinación no se activaría el movimiento dinámico interno, este acceso implícito, inicial, propio de cada hombre.

Sin embargo, el momento de la inclinación natural no elimina el momento de la decisión del acceso a Dios de parte del hombre, que se manifiesta absolutamente en un acto de adhesión. A la tensión donante de Dios corresponde, según Zubiri, la tensión del hombre en la adhesión. Tal adhesión desarrolla y cumple el inicial acceso a Dios: se trata de la respuesta positiva del hombre a la inicial atracción de Dios. Es «una acción positiva en la cual la persona no es llevada a Dios, sino que la persona acepta desde sí misma este su ser llevada, de un modo activo y positivo, a saber, "va a Dios" ${ }^{30}$. Ante todo, tal adhesión

29 Por esta teoría original de Xavier Zubiri, cf. I. EllacuRía (1964), «La religación, actitud radical del hombre», Asclepio, 16, pp. 97-155; A. Guy (1964), «La théorie de la religation selon Zubiri», Bullettin Hispanique, 66, pp. 391-395.

30 HD, p. 215. 
no asume el significado de un abandono, sino que se realiza a través de tres momentos precisos: sumisión, suplica y refugio.

El momento de sumisión explicita la disposición primordial del hombre con referencia a lo divino: es el reconocimiento de su ser relativo frente a la realidad absoluta que tiene su culminación en el acto de adoración. Pero, adherir significa también confiarse a Dios en cuanto posibilidad: es el momento de la súplica, es decir, el momento de la relación interpersonal a través de la cual el hombre, sin dejar de lado la realidad, pregunta a Dios «en las cosas y con las cosas $»^{31}$. En fin, la adhesión es consigna llena, apoyo sobre el cual poder estar: el hombre, en efecto, "se entrega a Dios como refugio no para actuar sino para ser ${ }^{32}$. En efecto, tales momentos no son más que una puntualización de la adhesión como único acto que compite al hombre en su acceso a Dios y que tiene su radicalidad formal en lo que expresamos cuando hablamos de fe. ¿Pero, en la perspectiva de la filosofía de Zubiri, qué es la fe? "Objeto de la fe: la verdad de un juicio ${ }^{33}$, escribe el filósofo. La fe se activa en la adhesión de mi persona a otro al que confiamos nosotros mismos. La fe es, por lo tanto, un confiar en la persona, y éste no puede sino implicar el creer en la verdad. Haber separado el ámbito de la fe del de la verdad es el gran error de la modernidad y de la filosofía de la religión. Pero bien visto, es el error de una parte de la teología cristiana cuando ha querido poner el problema de la verdad tan solo en el interior de una comunicación de fe: la fe es creer lo que Dios comunica. Pero la insuficiencia de una tal posición había ya sido estigmatizada en el siglo iv por San Agustín: no basta creer a Dios (credere Deo); es decisivo que tal fe se transforme en un radical creer en Dios (credere in Deum). La fe no es solo un acto a través del cual alguien se adhiere a una persona en cuanto trae la verdad, comunicándola, sino que es la verdad en que consiste en sí la misma persona. La fe es por lo tanto adhesión a una realidad personal en cuanto verdad. No se trata, es bueno precisarlo, de una verdad de tipo afirmativo, sino de la verdad de la realidad en cuanto tal: no «una propiedad del pensamiento, sino una propiedad de la realidad misma ${ }^{34}$. Vuelve nuevamente el concepto de verdad real, que aquí reviste el carácter de una "verdad personal", a través de los tres momentos canónicos de la verdad real: manifestación, firmeza y efectividad.

Creer, entonces, significa fiarse de una persona en su verdad personal y real: no en la verdad que comunica. En el caso de Dios, significa adherir a él en cuanto verdad personal y real. Pero sabemos que Dios es presencia trascendente en las cosas, y en modo único en el hombre. Por tanto creer en Dios en la fe significa últimamente «entregarse al propio fondo trascendente de mi persona $»^{35}$. El acto de fe constituye, así, un movimiento interno a la propia humanidad, a la propia trascendencia personal. Es un ir al fondo de sí mismo, a las propias exigencias y

\footnotetext{
31 HD, p. 217.

32 HD, pp. 217-218.

33 HD, p. 226.

34 HD, p. 229

35 HD, p. 231.
} 
evidencias originarias. El trato distintivo de tal acto es el aspecto personal. La fe tiene, por tanto, el carácter de una adhesión personal, de una certeza personal y de una opción personal. Cuando se dice que una persona tiene más o menos fe, en efecto, no se hace que constatar el carácter personal propio de cada hombre: tener más fe no significa tener más probabilidad, sino creer con más firmeza, con más energía. Tanto que la pérdida de tal certeza no expresa una pérdida de probabilidad o posibilidad, sino un aniquilamiento de la misma certeza, sea cual sea la causa de una tal pérdida. Pero tal adhesión y certeza personal necesitan de un último factor: nuestro personal movimiento de aceptación. Es verdad que nosotros somos "atraídos", inducidos por un poder que no depende de nosotros, pero tal inclinación natural para cumplirse —esto es por hacerse adhesión llena al ser - tiene necesidad de nuestro consentimiento: "solo haciéndola suya se convierte en entrega personal» ${ }^{36}$. Para que la fe se vuelva personal, necesita de una decisión por la existencia, una toma de posición, una elección que implica todos los factores de lo humano:

«Es una opción de toda nuestra realidad entera y no sólo de la inteligencia, del sentimiento o de la voluntad; una opción de nuestra realidad en orden a la figura radical y última del nuestro ser relativamente absoluto, del nuestro Yo» ${ }^{37}$.

Tal elección revela una última propiedad de esta adhesión personal: su carácter libre. La fe es tal sólo en la libertad radical, y uno es libre sólo cuando va al fondo de aquello por el cual estamos hechos, haciendo nuestra la atracción con la cual la verdad personal de Dios nos mueve hacia Él.

\section{SABER Y CREER: UNIDAD DEL ACTO INTELECTIVO}

«Porque el que Dios acontezca en mí es, en última instancia, sólo cosa de Dios, no es cosa mía. Dios acontece en mí, sépalo yo o no lo sepa, quiéralo yo o no lo quiera. Para que sea cosa mía hace falta algo más: hace falta que sea yo quien la haga mía ${ }^{38}$.

La adhesión personal del hombre implica un dinamismo según el cual a la iniciativa divina corresponde la adhesión del hombre para hacer que Dios pueda entrar formalmente en su acontecer. En esta dinámica se juega el nexo entre fe y conocimiento. El hombre puede perfectamente conocer la existencia de Dios desde un punto de vista puramente demostrativo, como un objeto entre otros en el universo. Dios es solo un objeto de conocimiento que no implica por sí mismo una adhesión personal de parte del hombre. El conocimiento de un teorema matemático, o un cualquier conocimiento demostrativo, puede no determinar necesariamente una adhesión: se puede tener un gran conocimiento

\footnotetext{
36 HD, p. 236.

37 Ibíd.

38 HD, p. 248.
} 
también de las demostraciones de la existencia de Dios sin, por esto, llegar a una fe. Y esto no porque no se pueda tener fe de lo que se conoce, sino porque conocer y creer son dos aptitudes diferentes estando también esencialmente unidas. Y esta unidad procede directamente del carácter gnoseológico de la fe: se puede adherir a algo, o a alguien, solo después de haber tenido una cierta intelección: «la conexión entre razón y fe se halla formalmente anclada dentro de la intelección y no fuera de ella ${ }^{39}$. Razón y fe representan, entonces, dos funciones distintas de la misma inteligencia.

Cada conocimiento es siempre, según Zubiri, una actualización de lo que es inteligido en la inteligencia y por tanto la función de ésta depende de la índole de lo que se está actualizando. No es la misma cosa conocer la realidad en su objetualidad y en su mentalidad. Mientras, en efecto, en el primer caso la función intelectiva llega al descubrimiento del objeto en su ipseidad, en el segundo caso la misma inteligencia es llamada a una tarea más compleja: a la función de descubrimiento de la realidad se añade aquella de la fundamentalidad que es el ámbito a través del cual se hace posible que mi realidad llegue a su fundamento. Conocer la realidad-fundamento - esto es, conocer a Dios, realitas fundamentalis - significa actualizar una realidad no como objeto presente en sí, sino como realidad fundante, una presencia que abre el ámbito de la fundamentalidad de mi yo y hace posible tal conocimiento, hace posible, esto es, la adhesión al fundamento de mi yo. El conocimiento de la realidad-fundamento, por lo tanto, constituye ya la posibilidad de la fe. En este modo Zubiri quiere superar las concepciones clásicas de la relación entre fe y razón, concebidas siempre en el interior de una dicotomía originaria entre el creer y el conocer ${ }^{40}$. Lo que, en cambio, es importante para el filósofo español es indicar una unidad más originaria y radical: la unidad entre conocimiento y el ámbito de adhesión en la intelección de Dios como realidad-fundamento. Y tal unidad radical se expresa en los términos de una posibilidad.

¿De qué se trata? La posibilidad concierne no solo la realidad en cuanto tal, sino también el modo a través del cual la realidad posible viene actualizada por mi inteligencia: las cosas reales posibles muestran, así, el ámbito de mis posibilidades reales. Lo real posible pide tomar posición, solicita una adhesión de la realidad personal a una determinada posibilidad. Es lo que Zubiri llama acto de apropiación, un acto a través del cual el hombre decide acerca de una posibilidad como modo del propio ser. El ámbito de la posibilidad, entonces, es tout court el ámbito de la voluntad: es voluntad de ser, o mejor, voluntad de verdad.

Università degli Studi di Bari Aldo Moro

Paolo Ponzio paolo.ponzio@uniba.it

[Artículo aprobado para publicación en este número extraordinario en noviembre de 2014]

39 HD, p. 250.

40 El credo ut intelligam o el intelligo ut credam, en efecto, según Zubiri, subrayan una unión entre fe y conocimiento en los términos de un pasaje: «la fe como camino "para” el conocimiento o el conocimiento como camino "para” la fe». HD, p. 253. 